\title{
Homeschool Journey's Affordances in Children's Performances within Rural Environment
}

\author{
Noor Ain Yatiman, Nor Fadzila Aziz, Ismail Said \\ Faculty of Built Environment, \\ Universiti Teknologi Malaysia, Johor, Malaysia \\ ismailbinsaid@gmail.com
}

\begin{abstract}
The study investigated children's performances during homeschool journey in a rural environment through their actualized affordances at a village in Johor, Malaysia. The study was conducted with fiftyfour middle childhood children through drawings, interviews and participant observation. The data were analyzed using qualitative content analysis. Children engaged more with natural elements rather than manmade elements and positively perceived, utilized and shaped the affordances. Therefore there is evidence to suggest that children recognized homeschool journey as their play spaces allowing them to interact with nature and developed their physical, social and cognitive skills, especially for children with high independent mobility.
\end{abstract}

Keywords: Children performances; natural environment; independent mobility; homeschool journey

eISSN 2398-4295 @ 2018. The Authors. Published for AMER ABRA cE-Bs by e-International Publishing House, Ltd., UK. This is an open-access article under the CC BY-NC-ND license (http://creativecommons.org/licenses/bync-nd/4.0/). Peer-review under responsibility of AMER (Association of Malaysian Environment-Behaviour Researchers), ABRA (Association of Behavioural Researchers on Asians) and cE-Bs (Centre for EnvironmentBehaviour Studies), Faculty of Architecture, Planning \& Surveying, Universiti Teknologi MARA, Malaysia.

DOI: http://dx.doi.org/10.21834/ajbes.v3i9.65 


\subsection{Introduction}

In recent years, children accessibility and engagement with natural environment was gradually declined. This situation certainly affected children's performances of physical, social and cognitive. Previous studies on children's environment found that nature is the most significant place to develop children's performances (Tai et al., 2006; Wilson, 2008). Nowadays, children spend a large proportion of their time at school (Londal, 2010), and homeschool journey becomes part of their everyday routine (Pooley, et al., 2005, Joshi et al. 1999). They walk, cycle, chat with friends, and even play along the journey. Therefore, the journey stimulates the physical (Spinney \& Millward, 2011), social and cognitive performances among children. Children in urban and rural area may have diverged homeschool journey experiences. Rural children have more affluent engagement with the natural environment as compared their urban counterparts (Pooley, et al., 2005). Therefore, this study aimed to investigate children's experiences during homeschool journey in the rural environment in order to identify the actualized affordances which stimulate their performances. To support this aim, two objectives were formulated: (1) to investigate children's experience during homeschool journey and (2) to identify children physical, social and cognitive performance during the journey. Most of the affordances in environment involved engagement with living things because many children love to play in natural environments (Wilson, 2008). Therefore, children in the rural area were observed to have greater opportunity to engage with the natural elements in their play.

\subsection{Literature Review}

Interaction with natural environment provides fundamental learning and play opportunities for children. Play is a fundamental vehicle for children's learning and play in nature can enhances the potential for learning through play (Wilson, 2008). The natural setting provides more diverse play spaces for learning opportunities and simultaneously will improve children's physical activities. From ecological perceptual psychology perspectives, the relationship between person and environment is looked into the theory of affordances. According to Gibson (1979), affordances of an environment are associated with the elements which offered to the users. For example, a tree can afford climbing branches, picking leaves, and breaking twigs which permits children's physical, social and cognitive skills. Gibson (1979) also stated "We must perceive to be able to move around, and we must move around to be able to perceive" (p.223). Movement means play to children which involve perceiving the environment through the children's senses. Hence, it is clearly shown that perception and mobility are closely connected. Perception is focused on finding the affordances of an environment. Perception and action are interrelated which through action a person can reveal new affordances and vice versa (Kytta, 2003).

Affordances are categorized into (1) levels of affordances, (2) taxonomy of affordances, and (3) types of affordances. There are three levels of affordances: perceived, utilized and shaped (Kytta, 2003), which perceived affordances is passively actualized, whereas utilized and shaped affordances are actively actualized. Perceived affordances are associated with the sense, utilized affordances are associated with an ability to use something, and shaped affordances are an ability to create things. Taxonomy of affordances was categorized based 
on children's action in various environments that was categorized into 10 categories of environmental quality including flat, relatively smooth surface, relatively rough slopes, greenery and wildlife, graspable or detached objects, attached objects, non-rigid attached objects, climbable features, aperture, microclimate, moldable material and water (Heft, 1988). The children interaction with the environment involved with two types of affordances including positive and negative. The positive affordances associated with the preference elements, while negative affordances associated with the elements that children disliked in the environment (Kytta, 2003). The environment will be considered affording children's play and learning activities when the positive affordances dominated the environment. Therefore, the Gibson's theory of affordances is useful for study in determining the functional properties of the homeschool journey environment.

\subsection{Method}

\subsection{Subject}

The experiences of children's homeschool journey were explored among 54 middle childhood children, aged 9-11 years old, at Sri Gunung Pulai village in Johor, Malaysia. They were attending an elementary school, which was located in the village. Types of children's mobility to school in the village have been classified into independent and dependent mobility. Independent mobility involves walking and cycling without adult supervision. While, dependent mobility includes cars or motorcycles with adult accompaniment. Permission to conduct research in school was obtained from the school's headmaster and parents. The research was divided into two, which $98 \%$ of the children participated on the first task, while $2 \%$ of the children were not included because of insufficient communication skills. Only $8 \%$ of participants of the task 1 were selected for the task 2, especially children with independent mobility. The selection considered the different routes taken by the children who consist from every corner of the village. The rational was to identify the affordances in various settings of the village.

\subsection{Measures}

Affordances of the homeschool journey were investigated by using visual methods which include drawing and video recording. The drawing method was designed to identify the elements that children have encountered along the journey. Children were asked to recall and draw their homeschool journey including their home, elements that they have encountered, and their school on A3 size paper. Interview was conducted to avoid misinterpretation of drawings and the conversation was recorded using a voice recorder. While, to assess more data on children's activities, children were observed in three days and their journey were recorded using a video camera.

\subsection{Procedure}

The first task, which included drawing and interview, was conducted in the classroom during one hour lesson; the first 45 minutes were allocated for drawing session and another 15 minutes for the interview. The task was assisted by four field researchers. Whereas the 
second task, the participant observation, was conducted during children's homeschool journey by six researchers. The observation lasted from 3 to 7 minutes of video recording. The task was assisted by field researchers and local residents.

\subsection{Analysis}

The set of data were analyzed using content analysis technique. Children's words on their experiences during the homeschool journey were bracketed and coded into twelve categories based on the categories of affordances by Heft (1988). While, the drawing was analyzed for the frequency of elements appeared in the drawing and only significant elements were coded into the categories. The responses were considered as affordances which were later classified into three categories including level of affordances, types of affordances and taxonomy of affordances.

\subsection{The limitation acknowledged}

The first limitation was time to conduct the survey. The study was conducted during school hours with limited time was given by the school's headmaster due to his concerns on children's learning session during school hours, especially for the core subjects. A second limitation was the study's methodology. The method followed the rules of conducting surveys with children (Ennew, 2009) including to respect the children by asking permission in whatever we do. Therefore, the survey was conducted with children's and parent's permission. The children who are cycling to school were informed to be followed, recorded and observed by field researchers. However, the children feel uncomfortable of being followed, recorded and observed by the field researchers which may affect the validity of data collection.

\subsection{Finding and Discussion}

\subsection{Level of affordances}

As shown in Figure 1, homeschool journey afforded 124 perceived, 89 utilized and 3 shaped affordances for rural children. It means that children engaged with passive than active activities.

The children were commonly engaged with perceived affordances includes seeing Hornbill, sniffing durian fruits to select a ripe one, and hearing the bird's song. While, utilized affordances includes climbing trees and cycling over a speed bump. Shaped affordances includes manipulating oil palm leaves to make pointer for reading Quran and plucking leaves as the false money for pretend play. The result suggests that children create and explore interesting things during their journey. However, children play during their journey was related to the limited time spent during the journey. The result was in contrast to the study by Said (2008) which found that the children play in home garden involved more with utilized affordances and not involved with time constraints in performing their activities. 


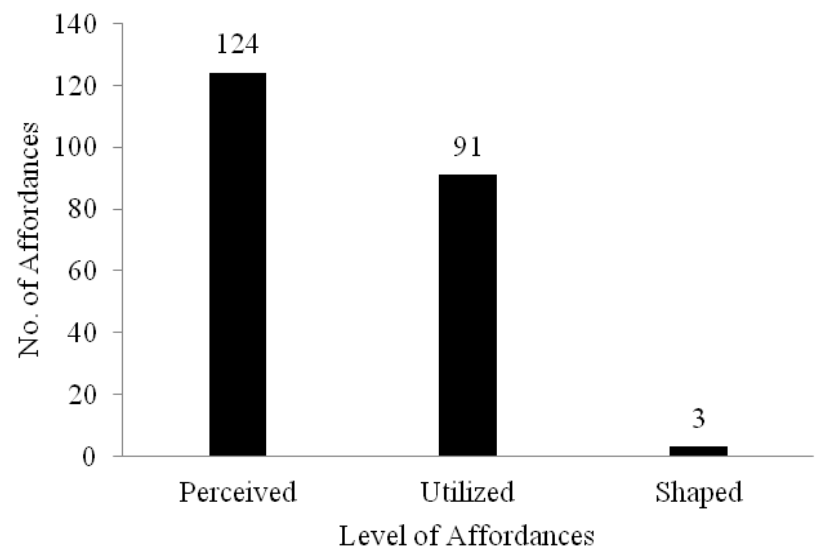

Fig. 1: Level of affordances in homeschool journey

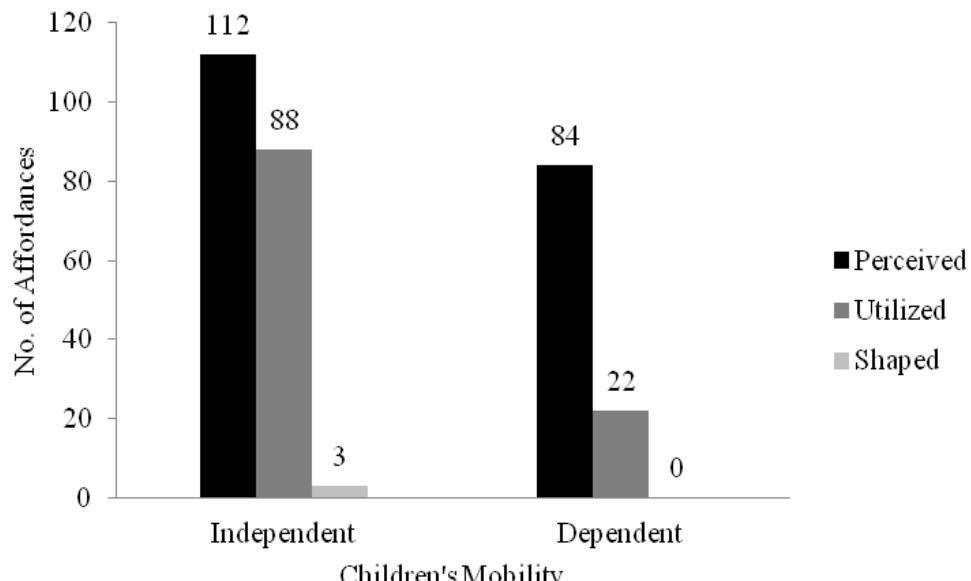

Fig. 2: Children's mobility to school

However, Figure 2 shows that children who were going to school independently have greater experiences of homeschool journey than children with dependent mobility. It was due to their ability in independently explored the surrounding without restriction (Romero, 2010) which allows them to make decisions about where to go, what to do and what to see. Children with independent mobility also more sensitive to the potential play possibilities offered by the surroundings (Romero, 2010). While, children with dependent mobility engaged more with passive affordances because they only manage to observe the outdoor environment from 
the car windows. They have restricted opportunities to engage and explore the environments because they were normally driven straight away to school. The finding was consistent with the study by Mitchell et al. (2005) who found that children with adult accompaniment may prevent the simplest of outdoor activity, which can build skills and attitude.

In sum, the children level of affordances in homeschool journey was influenced by the context of the study and the types of mobility to school. The context of the homeschool journey comprised of various physical elements which will be discussed in the taxonomy of affordances.

\subsection{Taxonomy of affordances}

Children's engagement with the elements in a rural area was classified according to Heft's and Kytta's taxonomy of affordances (Heft, 1988; Kytaa, 2003). This study concerns on the taxonomy of affordances of homeschool journey in a rural area has been modified and extended into twelve categories (see Figure 3 ). The finding shows that children were more frequently engaged with manmade elements $(n=35)$, vegetation $(n=31)$, and graspable object $(n=31)$. However, if the number of affordances for vegetation and animal were combined as natural elements, a total of 55 affordances indicate that children have more engagement with the natural elements than the manmade elements.

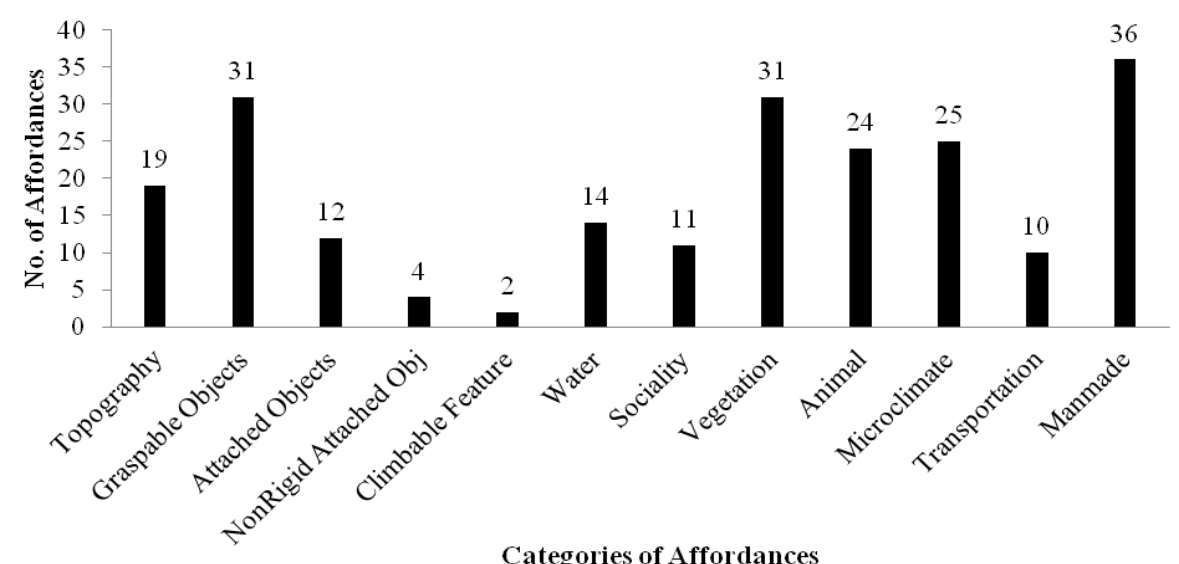

Fig. 3: Taxonomy of children's homeschool journey

Children engagement with manmade elements $(n=35)$ were categorized into residential, shop, community building, shelter, agricultural factory, and landscape elements. The residential house affords highest affordances including seeing friends, neighbor and relatives, and recognizing the types of house. The small shops afford children buying snacks and having breakfast before and after school. The result was consistent with the study by Joshi et al. (1999) suggesting that smaller shops were likely to be very interesting for children 
buying snacks. The finding shows that children were familiar with the neighborhood area due to their ability to locate the manmade elements correctly. There are evidences suggesting that homeschool journey encourages the development of children's spatial knowledge.

The affordances of vegetation $(n=31)$ were categorized into fruit trees, plantation trees, shaded trees, agriculture, ornamental, and field. The result found that the children were familiar with the vegetation around the village through their ability of recognizing different trees. Besides that, vegetation afforded multiple experiences for children. For example, for durian tree, they experienced seeing its flowers dropping onto the ground suggesting that the tree will bear fruits. The children even mentioned that they can identify a quality of durian fruit by smelling it. However, the most interesting experienced was the children were recognized a hiding place for bats inside the furling leaf. This suggests that the journey gives an opportunity for the children to explore nature freely and discover new knowledge. Therefore, natural elements offered various performances for children to discover new thing because of their constant change of shape, texture, color and smell (Tai et al., 2006). It is permitting children to fulfil their various instinctive play behaviors such as climbing trees and breaking twigs.

Some of the elements that demonstrated children's engagement with graspable objects $(n=31)$ included flat pebbles, fruits, leaves, twigs, as well as manmade element such as an umbrella. For examples, they throw pebbles into the river, collecting pebbles for slingshot wildlife, plucking fruits, and breaking twigs. It shows that graspable objects can be easily found at the area and manipulable by children in their play. Children playing with graspable objects or loose parts are involved with constructive play (Fjortoft, 2004).

In summary, the homeschool journey in the rural area is perceived by the middle childhood children as a play area which can stimulate their play, learning and development. The homeschool journey afforded many opportunities for children to interact more with natural rather than manmade elements, which expand their physical, social and cognitive skills.

\subsection{Types of affordances}

As illustrated in Figure 4, homeschool journey afforded six times more positive affordances $(n=187)$ than negative ones $(n=81)$ to the children. The positive affordances includes swimming and bathing in stream, cycling over puddles and feeling the splash, and cycling over speed bumps and feeling like flying. The negative affordances included fearing of monkey and ghost, and feeling tired of cycling uphill. The positive affordances were more than negative affordances suggesting that the functional properties of homeschool journey were positively perceived, utilized and shaped by the children. Thus, the result suggests that children perceived the homeschool journey in the rural area as their playscape and learning spaces. This happens to children with high independent mobility.

Therefore, the study suggests that natural elements affords more positive affordances for children during their homeschool journey. This finding was parallel with other studies at natural setting as such by Fjortoft (2004) at small forest who found that natural landscape influences children's physical activity and motor development. While a study by Bjorklid and Nordstrom (2007) suggested natural environment has a strong positive emotional value for 
children. The natural environment was viewed as a playground for children due to its ability that afford challenging and stimulating play environments.

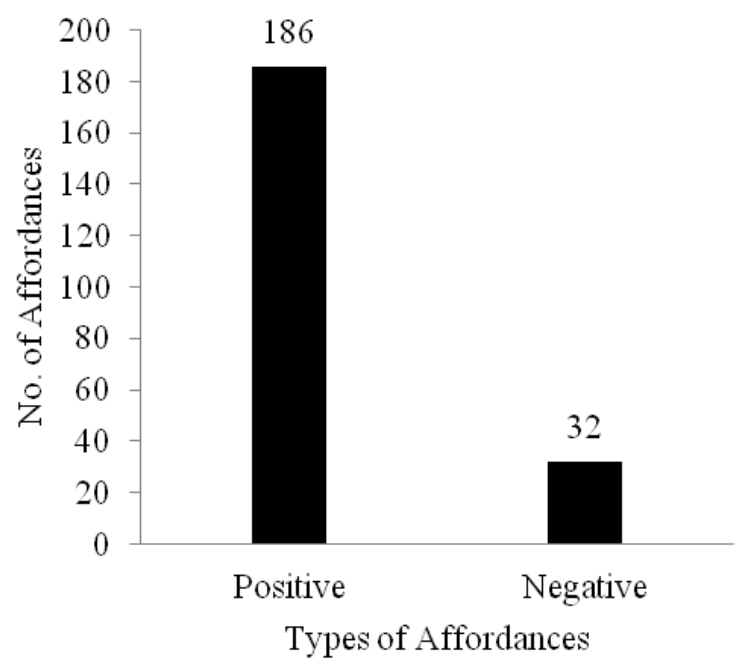

Fig. 4: Types of affordances in homeschool journey

\subsection{Conclusion and Recommendation}

In summary, homeschool journey at the rural area is a suitable place for children to develop their physical, social and cognitive performances. Most of their activities involved performatory and exploratory performance such as seeking, searching, climbing, sliding, plucking, collecting, and throwing. However, there were fewer activities that involved productivity performance which creating new things from natural elements due to the time constraints. The journey inspired the children feeling of excitement, wonder, joy, challenge and even fear. It means that the homeschool journey in a rural area affording a variety of elements allowing them to express their physical, social and cognitive skills. However, the methods applied in this study need further improvements that should be tested in the urban environment to make a comparison of children's performances at urban homeschool journey.

\section{Acknowledgements}

The study was funded by the Research University Grant Scheme (Q.J 13000.7121.00H58) by University Teknologi Malaysia. 


\section{References}

Bjorklid, P. and Nodstrom, M. (2007). Environmental Child-Friendliness: Collaboration and Future Research. Children, Youth and Environment, 17 (4): 388-401.

Ennew, J. (2009). The Right to be Properly Researched: How to Do Rights-based, scientific Research with Children. Bangkok: Black on White Publication.

Fjortoft, I. (2004). Landscape as Playscape : The Effects of Natural Environments on Children 's Play and Motor Development. Children, Youth and Environments, 14(2).

Gibson, J. (1979). The Ecological Approach to Visual Perception. New Jersey.

Heft, Harry (1988). "Affordances of Children's Environments: A Functional Approach to Environmental Description." Children's Environments Quarterly 5 (3): 29-37.

Joshi, M.S., MacLean, M. and Carter, W. (1999). Children's Journey to School: Spatial Skills, Knowledge and Perceptions of the Environment. British Journal of Developmental Psychology, 17, 125-139.

Kytta, M. (2003). Children in Outdoor Context: Affordances and Independent Mobility in the Assessment of Environmental Child Friendliness. Helsinki University of Technology, Espoo, Findland.

Londal, K., (2010). Revelations in Bodily Play: A Study Among Children in an After-school Programme. The Norwegian School of Sport Science.

Said, M. S. S. A. I. (2008). Middle Childhood Children Interaction with Home and Neighborhood Gardens in Urban and Rural Setting. 2nd International Conference on Built Environment in Developing Countries (ICBEDC 2008).

Spinney, J. E. L., \& Millward, H. (2011). School Travel Mode Choice and Characteristics of the Children, School and Neighborhood. Children, Youth and Environments, 21(2).

Pooley, C.G., Turnbull, J., and Adams, M. (2005). The Journey to School in Britain Since the 1940s: Continuity and Change. Blackwell Publishing on behalf of The Royal Geographical Society (with the Institute of British Geographers). Vol. 37, No.1: pp 43- 53.

Prezza, M. (2007). "Children's Independent Mobility: A Review of Recent Italian Literature." Children, Youth and Environments 17 (4): 293-318.

Romero, V. (2010). 'Children's Views of Independent Mobility during Their School Travels." Children, Youth and Environments 20 (2): 46-66.

Spinney, J. E. L., \& Millward, H. (2011). School Travel Mode Choice and Characteristics of the Children, School and Neighborhood. Children, Youth and Environments, 21(2).

Wilson, R. (2008), Nature and Young Children Encouraging Creative Play and Learning in Natural Environments. New York: Routledge. 